\title{
CLAVES PARA RECONOCER UNA AMISTAD VERDADERA. UNA REFLEXIÓN DESDE EL PENSAMIENTO DE MIGUEL DE UNAMUNO
}

\author{
ARRATE APARICIO MARCOS \\ Universidad Pontificia Comillas
}

\begin{abstract}
RESUMEN: En el presente artículo se expone una reflexión sobre la idea unamuniana de la amistad. Miguel de Unamuno, pensador existencial español, invita frecuentemente en sus escritos a replantearse la autenticidad de las relaciones que mantenemos con nuestros prójimos, con aquellos con quienes compartimos vida. Veremos que entiende la amistad como el enlace espiritual entre dos almas, como un amor compartido que se funda en la afección del espíritu, siendo justamente esa afección lo que nos permite el diálogo moral con nuestro amigo. Es evidente que fácil es toparse con personas con las que se pueda establecer una amistad superficial, y muy difícil encontrar a una persona en la que se pueda confiar plenamente y a la que nos podamos entregar por completo para mantener una amistad auténtica e imperecedera. Con el propósito de aprender a identificar una verdadera amistad, se pretenden analizar las claves que nos ofrece el pensamiento de Unamuno, principalmente sobre la base de sus escritos espirituales.
\end{abstract}

PALABRAS CLAVE: Unamuno; amistad; amor; sinceridad; soledad; inmortalidad; existencia.

\section{Clues to recognise a true friendship. A reflection from the thought of Miguel de Unamuno}

ABSTRACT: This article presents a reflection on the Unamuno's idea about friendship. Miguel de Unamuno, Spanish existential philosopher, frequently invites in his writings to reconsider the authenticity of the relations that we maintain with our neighbours, those whom we share life with. We will see that he understands friendship as the spiritual bond between two souls, as a shared love based on the affection of the spirit which allows us the moral dialogue with our friend. Obviously, it is easy to run into people with whom a superficial friendship can be stablished; conversely, it is very difficult to find a person fully faithful, whom we can completely devote ourselves to maintain an authentic and everlasting friendship. In order to learn to identify a true friendship, we aim at analyzing the clues that Unamuno's thinking offers us, mainly on the basis of his spiritual writings.

KEY WORDS: Unamuno; friendship; love; sincerity; solitude; immortality; existence.

¿Qué suponen los amigos en nuestra vida? ¿Qué esperamos cuando confiamos en ellos? ¿Es necesario sentir la soledad en una relación de amistad? ¿Qué la hace florecer? ¿Qué peso tiene el amor en esa relación confidencial?

Cuando encontramos un verdadero amigo sentimos, en el fondo, la necesidad de confesar lo siguiente: te necesito, te quiero, tengo el anhelo de hablar a solas contigo y con nadie más. Solo contigo, mi querido amigo y confidente. Siento la necesidad de tu presencia y busco en ti refugio, pues sospecho que solo tú vas a poder consolarme de aquellos pensamientos que me inquietan y desvelan. Siento también que eres parte de mi vida y tengo miedo de que este sentir, ese vínculo que a día de hoy nos une, un día se desvanezca y todo quede en el olvido. Quizás, pasados unos años, ni siquiera mi memoria rememore quién has sido o las peripecias que hemos compartido. Con el paso del tiempo, me olvidaré de 
todo y a ti te pasará lo mismo. Me olvidaré de ti y tú de mí. Nuestra amistad y los grandes momentos que hemos vivido juntos parece que ya no tendrán sentido. Han sido, pero no serán. Ya ni el recuerdo los mantendrá vivos. Y lo peor de todo es que sentimos que no podemos hacer nada para remediarlo; recuerda que somos seres finitos, limitados, que poseen una memoria frágil, base de nuestra conciencia personal, que olvida.

Es innegable que muchos de nosotros hemos sentido alguna vez esto mismo que acabo de exponer. Ser conscientes de que podemos olvidar a ese alguien que en un pasado consideramos nuestro amigo y fue un pilar capital de nuestra existencia nos produce tal dolor y tristeza que solo encontrará consuelo cuando nuestra memoria recuerde algo de lo que había olvidado. Ese reconocimiento, siempre finito, de lo pasado surge gracias al amor verdadero que un día depositamos en las personas que ya no están (físicamente) en nuestra vida. Es el recuerdo de ese amor, esa amistad al fin y al cabo, lo que anhelamos y esperamos que quede para siempre en nuestra «inconciencia» (sic) ${ }^{1}$.

Sin embargo, tal vez, con el transcurso de los años, no recordemos el porqué de su amor o incluso no rememoremos siquiera las grandes vivencias que compartimos juntos tiempo atrás. Ante esta realidad, don Miguel de Unamuno nos consuela afirmando que «cada nuevo amigo que ganamos en la carrera de la vida nos perfecciona y enriquece, más aún que por lo que de él mismo nos da, por lo que de nosotros mismos nos descubre $»^{2}$. Y así es. Esos amores, aunque parezca imposible, no se perderán jamás; son ellos los que nos hacen ser quienes somos hoy. La comunión que surge cuando comienza una amistad se traduce en el despertar de sentimientos, emociones e ideas de nuestro espíritu, que no hubieran florecido jamás de no haber formado parte de nuestra vida esta persona que nos ofrece cariño y comprensión para hablar, en palabras de Unamuno, de la «trágica seriedad de la vida».

Ahora bien, tenemos que tener presente que en ciertas ocasiones, o bien no somos capaces de reconocer al amigo que tenemos enfrente, o bien utilizamos este precioso vocablo cargado de humanismo y trascendencia de forma vacía. Con el propósito de aprender a identificar una verdadera amistad, analizaré las claves que nos ofrece el pensamiento de Miguel de Unamuno, principalmente sobre la base de sus escritos espirituales:

1 El dolor del que hablamos es, pues, previo a haber olvidado a nuestros seres queridos. Sufrimos porque tememos que nuestra condición de seres finitos nos impida recordar su ser y todas las peripecias que hemos vivido juntos «concientemente» (sic). Dice Unamuno, en este sentido, que «el remedio al dolor, que es [...] el choque de la conciencia en la inconciencia, no es hundirse en ésta, sino elevarse a aquélla y sufrir más. Lo malo del dolor se cura con más dolor, con más alto dolor». Cf. Unamuno, M., Del sentimiento trágico de la vida, Alianza Editorial, Madrid, 2013, p. 329.

2 Unamuno, M., «El secreto de la vida» (1906), en: Obras escogidas: ensayo, novela, teatro, poesía, Círculo de Lectores, Barcelona, 1987, p. 117. Este escrito también se encuentra en Miguel de Unamuno. Antología esencial, edición de Cirilo Flórez, Tecnos, Madrid, 2014, así como en Escritos sobre la ciencia y el cientificismo, edición de Alicia Villar, Tecnos, Madrid, 2017. 


\section{SENTIR LA SOLEDAD PARA RECONOCER EL PESO ESPIRITUAL DE NUESTRA EXISTENCIA}

Don Miguel hace hincapié en la necesidad de sentir la soledad en uno mismo para reconocer el peso espiritual de nuestra existencia y la de los demás. Lo que más peso espiritual tiene en nuestra existencia no es, para él, nuestra vida social, sino aquello que nace de nuestra propia vida concreta. Esto significa que si no conseguimos mirar adentro y desde dentro, desde ese no lugar donde sentimos nuestro espíritu, nos va a ser imposible encontrar un motivo para vivir y dar sentido pleno a nuestra existencia.

En el hombre interior es donde se cumplen las misteriosas fusiones de la vida espiritual. Es el contenido del hombre, su hondura y su conciencia, donde reposan todas sus ideas, siendo el espíritu la idea más compleja, viva y real que habita en él ${ }^{3}$. Unamuno entiende la conciencia como el ámbito de nuestras ideas, imaginaciones, deseos y sentimientos. Y considera que el mundo interior se ha de superponer al mundo exterior, a saber, al mundo de los fenómenos sensibles que nos sustenta. ¿Por qué? Porque «todo vive dentro de la Conciencia, de mi Conciencia; todo, incluso la conciencia de mí mismo, mi yo y los yoes de los demás hombres» ${ }^{4}$. Sentir y comprender la comunión entre nuestra conciencia y nuestro derredor, bien sea la naturaleza bien sean nuestros prójimos, es, entonces, la clave, apoyada en la fe, la esperanza y el amor, para afrontar el porvenir: ese único reino del ideal y de la libertad.

El principio de nuestra vida interior ha de ser el reconocimiento puro de nuestra pobreza cordial de espíritu, para así descubrir nuevos horizontes vitales y proyectar nuestra vida a la eternidad. Salir de la idea que de ti tenías, revelarte a ti mismo tu conciencia y personalidad, esa que no culminará hasta el acontecimiento de tu propia muerte, es el cimiento que se requiere para poder tener compasión con tu amigo. Y, para ello, se debe vivir al día anhelando la eternidad, pues solo así comprenderemos que la vida plena estriba en amarnos los unos a los otros.

Se puede intuir que es necesario estar a solas con nosotros mismos, para sentir esa soledad que es en un primer momento angustiosa pero que nos posibilita dialogar con nuestro espíritu y juzgarnos con severidad, reconociendo nuestras virtudes y defectos, si queremos conocer los suspiros de nuestros amigos. Pensemos, como observa Unamuno, que «el amor, cuando es puro y noble, crece con la distancia. Su alma está más cerca de mí cuanto más de mí

3 «Refiriéndonos a tales honduras, no cabe hablar de ideas y de espíritu como cosas distintas; allí una idea es un espíritu o parte de él, y allí nuestro espíritu es una idea, la más compleja, la más viva, la más real, por ser la más ideal». Cf. UnAmuno, M., «Sobre la consecuencia, la sinceridad» (1906) en Obras completas, Vol. VIII: Ensayos, edición de Ricardo Senabre, Biblioteca Castro, Fundación José Antonio de Castro, Madrid, 2007, p. 953. De ahora en adelante siempre que se haga referencia a las Obras Completas se tratará de esta misma edición de Ricardo Senabre.

4 Unamuno, M., "Civilización y cultura» (1896), en: Obras escogidas: ensayo, novela, teatro, poesía, p. 17. 
se aleje su cuerpo. Me la dejó en unas palabras, en una mirada, y él vive ya, y crece, y se desarrolla en mí» ${ }^{5}$. Esto quiere decir que solo vamos a reconocer la clase de amor que sentimos por otra persona cuando, al distanciarnos de ella y en el silencio que implica la soledad, lo evoquemos en nuestra conciencia. La serenidad que facilita el aislamiento nos permitirá buscar dentro de nuestra alma, resignarnos ante nuestras limitaciones y aceptarnos tal y como somos. Ello, a su vez, nos posibilitará ser justos con nosotros mismos y, consiguientemente, con nuestros seres queridos.

Los hombres solo consiguen sentirse verdaderamente hermanos cuando se oyen mutuamente en el silencio que produce la soledad. No existe diálogo más veraz que aquel que uno mantiene a solas consigo mismo. El aislamiento que produce la soledad es, por lo tanto, lo que nos permite encontrarnos a nosotros mismos y encontrar en nosotros a todos nuestros hermanos también en soledad. De modo que parece que, para don Miguel, ese amor implicado en toda amistad, eso que podríamos denominar amor amistoso, solo se encuentra y reconoce en la soledad de uno mismo y en la de los demás. Recogerte en tu mismidad y confesarte con tu propia conciencia para reconocerte a ti mismo también como prójimo, como amigo de tu amigo, es necesario para aprender a amar a los otros. Solo así seremos capaces de darnos a los demás de la mejor manera posible: por entero y de forma indivisible.

Todo esto sucede porque estando a solas es difícil huir de nosotros mismos y de nuestra propia humanidad; cuando escuchas a tu corazón, no te queda más remedio que ser justo contigo mismo y hacerlo patente en pensamiento y palabras. Saber estar solos nos capacita para sentir el ser de nuestros amigos e identificar el amor en el que se cimienta nuestra amistad, ya que echándole de menos nos daremos cuenta de lo importante que es para nosotros, en nuestra vida, en nuestra conciencia.

Por consiguiente, Unamuno sostiene que hemos de creer previamente en nuestra propia existencia sustancial para poder creer en la existencia sustancial de nuestros prójimos. De hecho, no creer lo suficiente en la propia existencia sustancial es la razón principal por la que amamos tan poco al prójimo y que, consecuentemente, no se entablen muchas relaciones de amistad verdaderas. Dice nuestro autor al respecto que "todo el que de veras cree en su propia existencia, anhela sellar con ella las existencias de los demás» ${ }^{6}$. De modo que la fe robusta en nuestra existencia es la mejor medicina para acrecentar y reconocer el sentimiento que inunda nuestro espíritu al eternizarse en él nuestro amigo. Y evidente es que para ello se precisa de imaginación, la facultad creadora de sentido y fuente de caridad y amor.

\footnotetext{
5 Unamuno, M., «Soledad» (1905) en OC, Vol. VIII: Ensayos, p. 779.

6 Unamuno, M., "Plenitud de plenitudes y todo plenitud» (1904) en Obras escogidas: ensayo, novela, teatro, poesía, p. 93. También se encuentra este escrito en la ya citada obra Miguel de Unamuno. Antología esencial, edición de Cirilo Flórez.
} 
2. DESCUBRIR EL SECRETO PROFUNDO Y MISTERIOSO QUE UNE TODA RELACIÓN CONFIDENCIAL

Unamuno insiste repetidamente en que cada persona es única e insustituible y que en serlo a conciencia es en lo que debe radicar nuestro principal empeño vital. Esto es crucial para hacer frente a lo que, para él, es el único verdadero afán que existe para los hombres todos: la cuestión humana. Se trata, en sus propias palabras, «de saber qué habrá de ser de mi conciencia, de la tuya, de la del otro y de la de todos, después de que cada uno de nosotros muera ${ }^{7}$. De manera que la inmortalidad del alma, la eterna y única verdadera cuestión humana, solo se puede hacer frente cuando no tememos sentir la soledad en nuestro espíritu.

Sin embargo, hemos de tener presente que, lamentablemente, hay muchas personas que no sienten el valor de su propio espíritu, de su ser y su existir, y no tienen la necesidad de escucharse a sí mismos. No sentirse espiritualmente implica, para don Miguel, no tener capacidad para abrazar el alma con los mismos brazos del alma, no sentir ese «bulto» que incita a sentir, no poseerse y ni siquiera tener la intuición de la propia sustancialidad. Desaparece de sus vidas, entonces, el deseo de persistencia, pues sienten el mundo como un fenómeno y, como consecuencia, no tienen el anhelo de ser espiritualmente los otros para conseguir serlo todo, ser la totalidad de las cosas visibles e invisibles, eternamente. En estos casos, un amigo verdadero debe percatarse de tal carencia y asumir la iniciativa de inculcarle el amor por la propia persistencia inacababable. Solo así comenzará a sentir ese amor por la vida que no culmina en nada más que en tener fe en nuestra propia inmortalidad: el «manantial de la vida íntima del espíritu».

Bien sabemos que para don Miguel el espíritu íntimo de uno es indelegable. También sabemos que, para él, lo primero es llenarse de sí mismo para después desbordar y volverse sobre los demás. Pero lo que todavía no sabemos es que él incitaba siempre a los hombres a actuar como los grandes poetas, los hombres enamorados del ideal, que nos muestran su propia alma. Se trata de hombres espirituales y soñadores, que se guían por el corazón y nos ofrecen un mundo personalizado. El corazón, el cual corresponde al nivel sapiencial de la condición humana, tiene la facultad de ver más claro y más lejos de lo que la cabeza puede hacer, lo que facilita la intuición de la existencia de un yo espiritual, profundo y permanente en el que habitan misteriosas y valiosas potencias humanas ${ }^{8}$.

7 Unamuno, M., «Soledad» (1905) en OC, Vol. VIII: Ensayos, p. 781.

8 Unamuno clasifica a los hombres, basándose en las cartas a los Romanos y en la primera a los Corintios de Pablo de Tarso, en carnales, intelectuales y espirituales. Mientras que describe a los carnales como brutos e incultos, y a los intelectuales como los hombres de sentido común y de lógica, de recto juicio y claro criterio, precisa que los espirituales son «[...] los soñadores, los que llaman aquéllos con desdén místicos, los que no toleran la tiranía de la ciencia ni aun la de la lógica, los que creen que hay otro mundo dentro del nuestro y dormidas potencias misteriosas en el seno de nuestro espíritu, los que discurren con el corazón $[\ldots]$ ». Y matiza que «espirituales y no intelectuales han sido los más de los grandes poetas», Cf. «Intelectualidad y espiritualidad» (1904) en $O C$, Vol. VIII: Ensayos, p. 615. Ver también Miguel de Unamuno. Antología esencial, edición de Cirilo Flórez. 
Parece, entonces, que una persona que valora la amistad ha de ser como el poeta que se da a sí mismo con la única intención de revitalizar la espiritualidad dormida de su lector. Consigue así no solo reavivar en su espíritu una visión sensata y fecunda de su ser, sino también procurar que nunca más vuelva a delegar su intimidad de espíritu y sea capaz de asumir por sí mismo sus esperanzas y consuelos. Hemos de ser personas espirituales que ayudan a su amigo tanto a revelar su alma al desnudo como a contemplar el mundo entero hecho hombre. Esto reforzará su fe en sí mismo, y además le impulsará a reconocer su personalidad, su propia alma, lo que verdaderamente es.

De esta manera, dándonos al otro sin buscar recompensa alguna y sin tener miedo al compromiso, podremos influir en el crecimiento del alma de la persona a quien queremos. Ser su confesor, hablar con él por separado con la pretensión de inquietarlo por dentro y ahondar juntos en sus entrañas espirituales es lo que se necesita para que logre descubrir en ellas la fuente de su vida. Un amigo que comulgue en humanidad con nuestro espíritu, sepa penetrar en nuestro interior y sea capaz de empatizar con nuestro sentir y nuestras ideas es lo que requiere toda persona para tomarse la vida en serio, ser su dueño y nunca su esclavo.

Así pues, desnudar nuestra alma ante nuestro amigo es una forma de entregarnos a él, pero, como ya hemos advertido, antes hemos de buscar la verdad que habita en nuestro interior. Ese deseo de querer engrosar y henchir nuestro yo en el de nuestro amigo, una vez sentido nuestro propio peso existencial, supone que nuestro espíritu esté siempre activo, vivo y en permanente movimiento para con nosotros mismos, nuestros prójimos y la naturaleza en la que habitamos.

En la filosofía unamuniana se puede intuir que el amigo íntimo es aquel a quien, sin tú revelárselo, descubre tu secreto de vida, el misterio de tu corazón. Es esa persona con quien hablamos de todo menos de ese sentimiento, esa idea, que es la verdadera causante de nuestra comunión espiritual con él. Hay un secreto profundo y misterioso que es el promotor de toda relación confidencial, y que no se suele exteriorizar dado que es la misma raíz de ese vínculo. Pese a que nunca nos revelamos este secreto común, basta con una sola mirada de esa persona que se convierte en nuestro amigo, como matiza Unamuno, para que adivine nuestro secreto, de la misma forma que nosotros adivinaremos el suyo, y sea el conocimiento de ese misterio que fundamenta vuestra vida lo que nos una. Solo necesitamos mirarnos atentamente a los ojos para comunicarnos y conocer, en parte, el interior de aquel a quien miras. Yo no soy solo quien tú miras, ni tú eres solo lo que veo yo. Lo somos todo y no somos nada, ya que hay mucho más que lo que expresan esos ojos que reciben tu mirada y que te contestan con otra ${ }^{9}$.

Se puede deducir que, para don Miguel, la verdadera amistad nace en el momento que el secreto de nuestra vida es descubierto por la persona con la que hemos mantenido conversaciones de gran intimidad y confianza que le han

9 Cf. Unamuno, M., «El secreto de la vida» (1906), en: Obras escogidas: ensayo, novela, teatro, poesía, pp. 117-129. 
permitido conocer el misterio de nuestro corazón, de la misma forma que a nosotros nos han permitido conocer el suyo. Por ello no hace falta exteriorizar y revelar tal secreto a un amigo, dado que, a nuestro juicio, toda amistad verdadera se diferencia de la amistad superficial en el hecho de que echa raíces en las entrañas del alma del otro.

Conocemos el secreto íntimo de su vida porque nos lo ha dicho a solas, cuando se alejó de nuestra presencia. En la distancia los hombres aparecemos tal y como somos, o sea como hombres rebosantes de eternidad e infinitud, debido a que nos escuchamos tanto a nosotros mismos como a nuestro prójimo en el silencio de nuestro y su corazón. En el momento en el que recibimos algo del espíritu de nuestro amigo que renueva el nuestro, su reflejo queda ya inmerso en nosotros. Esto quiere decir que gracias a que nuestro amigo ha vaciado su espíritu, desnudado sus entrañas espirituales con nosotros, nuestro yo ya no es el de antes, pues ahora atesoramos en el fondo de nuestra alma el yo de un nuevo amigo que forma irremediablemente parte de nuestro ser. Ese será el instante en el que nos percataremos de que nos necesitamos mutuamente para consolarnos en nuestras necesidades afectivas y volitivas, a saber, en aquello en lo que se fundamenta el secreto de la vida: en nuestra hambre de inmortalidad.

\section{AMOR Y SINCERIDAD}

El amor, según Unamuno, vive de recuerdos y esperanzas, por lo que, como ya hemos comentado, solo en la serenidad que provoca la soledad, buscando dentro de nuestra alma, vamos a ser conscientes de la clase de amor que sentimos para con esa persona. El amor amistoso, en nuestro caso, comienza, como cualquier otro amor, con la comunión espiritual, ya que cada vez que entablas una nueva amistad te sientes renovado y espiritualizado. El sentimiento interior, ese amor único y leal, es lo que nos impulsa a hacer la valoración y la significación del ser de la persona que se convierte en nuestro amigo. Amar es compadecerse de alguien, y solo quien se conoce por dentro es capaz de compadecerse de sí mismo y compadecer a los demás. Ese compadecimiento en el otro se traduce en compasión, y de la compasión mutua surge el amor ${ }^{10}$.

Unamuno subraya que para amar verdaderamente a los otros hemos de dejar en segundo lugar el "ama a tu prójimo como a ti mismo», para centrarnos primordialmente en el "ámate a ti mismo». Porque, efectivamente, aunque sorprenda, hay muchas personas que no son capaces de amarse a sí mismas y esto es capital para saber y poder amar a los demás.

Don Miguel ampara una ética solidaria que se cimienta en el amor, la compasión y el sentido de justicia. El hombre, como ser que siente de forma

10 «La compasión es, pues, la esencia del amor espiritual humano, del amor que tiene conciencia de serlo [...]. El amor compadece, y compadece más cuanto más ama». Cf. Unamuno, M., Del sentimiento trágico de la vida, p. 175. 
irremediable su vulnerabilidad, busca la compañía de los otros siguiendo sus instintos naturales. Nadie nos obliga, por ley natural, a entablar amistad con el otro; es nuestra afección lo que nos incita a dar el paso por la necesidad que sentimos de compartir nuestra vida con él. Se puede decir, según lo que hemos expuesto, que la amistad es un lazo espiritual entre dos almas, un amor compartido que se funda en la afección del espíritu. Y es justamente esa afección lo que nos permite el diálogo moral con nuestro amigo y, gracias a ello, conocer la hondura de sus entrañas espirituales.

Por todo ello, nuestro autor reclama el saber para la vida y la sed de verdad. Él entiende la verdad, junto con Kierkegaard, como veracidad y autenticidad, como la coherencia entre las ideas y la vida. Recordemos que «el culto a la verdad por la verdad misma es uno de los ejercicios que más eleva el espíritu y lo fortifica $»^{11}$. La verdad es creer y obrar de todo corazón y con toda el alma. Buscar la verdad por la verdad misma y vivir con verdad la vida ha de ser el fundamento de nuestra existencia, pues esto es lo que nos lleva a realizar la acción más pura y noble.

Cuando estamos a solas, refugiados en la soledad de nuestro corazón, es cuando somos sinceros con nosotros mismos y oímos decir la verdad a los demás. La suprema virtud de un hombre, la humildad más verdadera, es, según Unamuno, la sinceridad. Si todos dijésemos siempre la verdad, o sea si fuésemos completamente sinceros con nosotros mismos y con aquellos con quienes compartimos vida, nos entenderíamos mucho mejor y más pronto sentiríamos una honda compasión y piedad mutua. Las palabras que dirigimos al otro han de ser siempre consecuentes con nuestros pensamientos, de la misma forma que nuestro sentir debe ir acorde con nuestro proceder. Hay que mostrarse tal cual se es, para lo que se necesita tener fe tanto en sí mismo como en el otro. Y para creer en sí mismo no se debe precisar que los demás crean en ti, ya que solo entregándonos plenamente y sin reserva a la plenitud que desprende la propia vida conseguiremos dicho fin.

Por lo tanto, comprometernos con el otro no significa decirle aquellas supuestas verdades que él quiere escuchar, sino aquellas que creemos que son las más convenientes que conozca o recuerde en ese momento. Nuestras verdades no van a ser sus verdades, pero cierto es que tales verdades le pueden ayudar en su camino vital. Ser insinceros con nuestro prójimo supone también hacernos traición a nosotros mismos; no tenemos que ser hipócritas, pues, según Unamuno, «esto llega a envenenar las fuentes mismas de la vida moral íntima» ${ }^{12}$. A nuestro juicio, no es amigo verdadero aquel que busca el beneficio que puede sacar de la unión de su alma con otra. Una amistad no es una relación que se deba trabar en el interés de satisfacer las necesidades vitales. Tenemos

11 Unamuno, M., "Verdad y vida» (1908), en: Miguel de Unamuno. Antología esencial, edición de Cirilo Flórez, p. 216. Este escrito también se puede encontrar en Escritos sobre la ciencia y el cientificismo, edición de Alicia Villar.

12 Unamuno, M., «Sobre la consecuencia, la sinceridad» (1906) en OC, Vol. VIII: Ensayos, p. 940. 
que dar lo que nos sobra y no pedir lo que nos falta. La amistad no tiene que ser un medio por el cual beneficiarte en tu vida, sino un fin cuyo único objeto sea la amistad misma. Esta falta de solidaridad y sinceridad para con los hombres sucede cuando la individualidad carece de espiritualidad ${ }^{13}$.

La amistad verdadera, volvemos a insistir en lo mismo, supone desnudar las entrañas de nuestro espíritu para con nuestro amigo, confiar profundamente el uno en el otro, y fundamentar siempre la relación en el amor, la sinceridad y el respeto. Esto significa que no debemos quedarnos en silencio sin decirle lo que le es conveniente saber. El diálogo fundamentado en la pureza de intención y la bondad es el alimento necesario para enriquecer la compenetración de las dos almas, de nuestras voluntades, y con ella las raíces de nuestra amistad. Pero cierto es que fácil es toparse con personas con las que se puede establecer una amistad superficial, y muy difícil encontrar a una persona en la que puedas confiar plenamente y a la que te puedas entregar completamente para mantener una amistad verdadera e imperecedera.

En conclusión, el fuerte vínculo que se establece en una relación de amistad florece en el momento en el que la espiritualidad inconsciente que habita en cada hombre se reaviva gracias a que los amigos, en su soledad, se invitan mutuamente, sin pretenderlo, a mirar en su interior y compartir ese potencial íntimo que descubren. Conoceremos así los defectos espirituales de nuestro amigo, pero también sus virtudes. Lo vivido y hablado con él bastará para avivar nuestra compasión, fundamento de la moral, y, con ello, sentiremos la necesidad de compadecerle, y nos esforzaremos por entender qué es lo que realmente le preocupa y desvela. Nuestra vida pasa, pero nosotros quedaremos eternamente, por lo que hemos de despertar de las honduras de nuestro ser también el anhelo de un mundo más humano y una vida más plena.

Así pues, queda claro que cuando tú, mi amigo, no estés conmigo, cuando ya no formes parte de mi vida o hayas partido al más allá, seguirás estando presente en mi interior. Las vivencias que he compartido contigo han hecho que yo, hoy, sea quien soy y como soy. Tu vida, mi amigo, mi querido confidente, no me pertenece; nunca me ha pertenecido y nunca me pertenecerá. Y yo sufro porque en un pasado te amé y ahora te sigo amando, pero preveo que ese amor con el tiempo perderá intensidad al tenernos irremediablemente que despedir. Tú de mí y yo de ti. Y así será. Nuestra condición de seres contingentes, destinados a la muerte, nos infunde tal incertidumbre vital que no permite que nada de lo finito, ni siquiera el amor amistoso, satisfaga completamente nuestro espíritu. De ahí que no podamos decir que la vida son los recuerdos que uno recuerda, ya que nuestro yo queda constituido tanto por lo que nuestra memoria consigue recordar como por lo que queda en el olvido.

13 Cf. VIllar, A., "El orden del amor en Miguel de Unamuno», en: Dialegesthai. Rivista telematica di filosofia [in linea], 2014. Recuperado de: http://mondodomani.org/dialegesthai/ ave01.htm. 
Vive cada uno en su descendencia, en todos y en cada uno de los que derivan de él según la carne, y vive también en todos y en cada uno de los que reciben los efluvios de su espíritu. Te trasmites todo y entero en todas y en cada una de tus obras y de tus acciones; en un gesto tuyo va tu espíritu completo ${ }^{14}$.

\section{BiBLIOGRAFÍA}

Floréz, C. (2014). Miguel de Unamuno. Antología esencial. Madrid: Tecnos.

Unamuno, M. (1970). Diario Íntimo. Madrid: Escelicer.

Unamuno, M. (1987). Obras escogidas: ensayo, novela, teatro, poesía. Barcelona: Círculo de Lectores.

Unamuno, M. (2005). Del sentimiento trágico de la vida en los hombres y en los pueblos; y Tratado del amor de Dios, edición de Nelson Orringer. Madrid: Tecnos.

Unamuno, M. (2007). Obras completas, edición de Ricardo Senabre. Madrid: Biblioteca Castro, Fundación José Antonio de Castro.

Unamuno, M. (2013). Del sentimiento trágico de la vida. Madrid: Alianza Editorial.

Unamuno, M. (2015). Mi confesión, edición de Alicia Villar. Salamanca: Sígueme: Universidad Pontificia Comillas.

Unamuno, M. (2017). Escritos sobre la ciencia y el cientificismo, edición de Alicia Villar. Madrid: Tecnos.

Villar, A. (2014). «El orden del amor en Miguel de Unamuno». Y en: Dialegesthai. Rivista telematica di filosofia [in linea]. Recuperado de: http://mondodomani.org/dialegesthai/ave01.htm.

[Artículo aprobado para publicación en enero de 2018]

14 Unamuno, M., «Plenitud de plenitudes y todo plenitud» (1904), en: Obras escogidas: ensayo, novela, teatro, poesía, p. 94. 